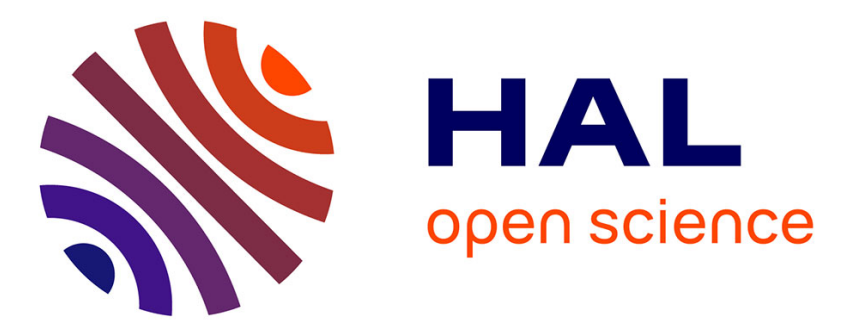

\title{
Methyl Internal Rotation in the Microwave Spectrum of Vinyl Acetate
}

\author{
Ha Vinh Lam Nguyen, Atef Jabri, Vinh Van, Wolfgang Stahl
}

\section{To cite this version:}

Ha Vinh Lam Nguyen, Atef Jabri, Vinh Van, Wolfgang Stahl. Methyl Internal Rotation in the Microwave Spectrum of Vinyl Acetate. Journal of Physical Chemistry A, 2014, 118 (51), pp.1213012136. 10.1021/jp5075829. hal-03183158

\section{HAL Id: hal-03183158 https://hal.science/hal-03183158}

Submitted on 27 Mar 2021

HAL is a multi-disciplinary open access archive for the deposit and dissemination of scientific research documents, whether they are published or not. The documents may come from teaching and research institutions in France or abroad, or from public or private research centers.
L'archive ouverte pluridisciplinaire HAL, est destinée au dépôt et à la diffusion de documents scientifiques de niveau recherche, publiés ou non, émanant des établissements d'enseignement et de recherche français ou étrangers, des laboratoires publics ou privés. 


\title{
Methyl Internal Rotation in the Microwave
}

\section{Spectrum of Vinyl Acetate}

\author{
Ha Vinh Lam Nguyen ${ }^{* a, b}$, Atef Jabri ${ }^{b}$, Vinh Van $^{a}$, and Wolfgang Stahl ${ }^{a}$ \\ ${ }^{a}$ Institute of Physical Chemistry, RWTH Aachen University, Landoltweg 2, D-52074 Aachen, \\ Germany \\ ${ }^{\mathrm{b}}$ Laboratoire Interuniversitaire des Systèmes Atmosphériques (LISA), CNRS UMR 7583/IPSL et \\ Universités Paris Est UPEC \& Paris Diderot UPD, Université de Paris Est, 61 avenue du Général \\ de Gaulle, F-94010 Créteil cedex, France
}

\begin{abstract}
The rotational spectrum of vinyl acetate, $\mathrm{CH}_{3}(\mathrm{CO}) \mathrm{OCH}=\mathrm{CH}_{2}$, was measured using two molecular beam Fourier transform microwave spectrometers operating in the frequency range from 2 to $40 \mathrm{GHz}$. Large splittings up to $2 \mathrm{GHz}$ occurred due to the internal rotation of the acetyl methyl group $\mathbf{C H}_{3} \mathrm{CO}$ with a $V_{3}$ potential of $151.492(34) \mathrm{cm}^{-1}$, much larger than the barrier of approximately $100 \mathrm{~cm}^{-1}$ often found in acetates. The torsional transitions were fitted using three different programs XIAM, ERHAM, and BELGI-Cs, whereby the rotational constants, centrifugal distortion constants, and the internal rotation parameters could be determined with very high accuracy. The experimental results were supported by quantum chemical calculations. For a conformational analysis, potential energy surfaces were calculated.
\end{abstract}


KEYWORDS: rotational spectroscopy, conformational analysis, ab initio calculations, large amplitude motion

\section{INTRODUCTION}

The microwave spectroscopic investigations on allyl acetate ${ }^{1}$ have shown that the barrier to internal rotation of the acetyl methyl group is $98.093(12) \mathrm{cm}^{-1}$, almost the same as that found for a series of alkyl acetates. Starting from the barriers of 102.413(20) $\mathrm{cm}^{-1}$ and $101.606(23) \mathrm{cm}^{-1}$ in methyl acetate ${ }^{2}$ and ethyl acetate, ${ }^{3}$ respectively, a barrier of approximately $100 \mathrm{~cm}^{-1}$ was always found when the alkyl chain is longer, like in the case of n-propyl acetate $\left(103.341(18) \mathrm{cm}^{-1}\right),{ }^{4} \mathrm{n}$ butyl acetate $\left(99.66(36) \mathrm{cm}^{-1}\right),{ }^{5} \mathrm{n}$-pentyl acetate $\left(102.4646(39) \mathrm{cm}^{-1}\right)^{6}$ up to $\mathrm{n}$-hexyl acetate $\left(99.759(28) \mathrm{cm}^{-1}\right){ }^{7}$ Even when the alkyl chain is branched like in isopropyl acetate ${ }^{8}$ and isoamyl acetate, ${ }^{9}$ the internal rotation barrier of the acetyl methyl group seems to be unaffected. Back to the case of allyl acetate, the allyl group does not affect the acetyl methyl barrier either; however, there is a long distance between the double bond and the methyl rotor. It is thus interesting to study vinyl acetate, where the double bond is attached directly to the carboxyl group and $\pi-$ electron conjugation becomes possible.

The free-jet millimeter absorption spectrum of vinyl acetate has been already investigated by Velino et al. in the frequency range from 60 to $80 \mathrm{GHz} .{ }^{10}$ In this study, a barrier to internal rotation of $155.07(9) \mathrm{cm}^{-1}$ for the acetyl methyl group was reported, which is considerably higher than the barrier of about $100 \mathrm{~cm}^{-1}$ found for all other saturated alkyl acetates aforementioned as well as for allyl acetate. ${ }^{1}$ A global fit using the program XIAM $^{11}$ was carried out for 101 transitions with $3 \leq J \leq 25$ and $3 \leq K_{a} \leq 5$. Unfortunately, the experimental resolution of $40 \mathrm{kHz}$ of the millimeter spectrometer in Bologna was not in the same order of magnitude for a reasonable comparison with the resolution of $2 \mathrm{kHz}$ for the microwave spectra measured in 
Aachen. A standard deviation of $0.08 \mathrm{MHz}$, which is twice the stated experimental resolution, could be achieved while 14 parameters were fitted. We thus decided to remeasure vinyl acetate using two molecular beam Fourier transform microwave (MB-FTMW) spectrometers. Using three programs, XIAM, ${ }^{11}$ ERHAM, ${ }^{12}$ and BELGI-Cs,${ }^{13}$ which are available at the web site given in Ref. 14, we expected to achieve better standard deviations. Afterwards, the gas phase structure of vinyl acetate was determined by comparing the experimental parameters with the results from quantum chemical calculations.

\section{MICROWAVE SPECTROSCOPY}

Experimental setup. All spectra were recorded in the frequency range from 2 to $40 \mathrm{GHz}$ using two MB-FTMW spectrometers, which are modified versions of the spectrometers described in Refs. 15-17. Vinyl acetate was obtained from Merck Schuchardt OHG, Hohenbrunn, Germany, and used without further purification. A gas mixture containing $1 \%$ substance in helium at a total pressure of 60 to $110 \mathrm{kPa}$ was used throughout. We chose helium as carrier gas because the cooling is not as effective as with argon or neon, and therefore also higher $J$ levels can still be observed.

The spectrometers can be operated in two different modes, the high resolution mode and the scan mode. Since the rotational constants reported in Ref. 10 possess sufficient accuracy, all spectra could be measured directly in the high resolution mode. All lines are split into doublets due to the Doppler effect; the molecular transition frequency is the center frequency. The splittings depend on both, the center frequency and the velocity of the molecular beam. Figure 1 illustrates a typical spectrum in the high resolution mode. A broadband scan in the frequency range from 19100 to $19900 \mathrm{MHz}$ was also recorded; two sections of it are shown in Figure 2 as an example of the A-E splittings. 
Measurements. First, the rotational constants and barrier to internal rotation of the acetyl methyl group from Ref. 10 were taken to predict the microwave spectrum using the program XIAM. In total, $90 \mathrm{~A}$ and $101 \mathrm{E}$ species with $0 \leq J \leq 15$ and $0 \leq K_{a} \leq 4$ and wide A-E splittings up to $2 \mathrm{GHz}$ could be found easily. They are all very intense $b$-type transitions. The line width is from 20 to $40 \mathrm{kHz}$ (see Figure 1), much larger than the value of $1 \mathrm{kHz}$ found for the $1 \leftarrow 0$ transition of OCS at $12 \mathrm{GHz} \cdot{ }^{18}$ In some transitions, splittings up to $10 \mathrm{kHz}$ could be resolved. We attribute these splittings and the large line widths to spin-spin and spin-rotation couplings of the protons, which will not be considered further.

Fits. In a next step, the rotational constants $A, B, C$, the centrifugal distortion constants $\Delta_{J}, \Delta_{J}$, $\Delta_{K}, \delta_{J}, \delta_{K}$, the $V_{3}$ potential, the polar-coordinate $\delta$, and the moment of inertia were fitted with the program XIAM. The angles between the internal rotor axis and the principal axes were derived from $\delta$ and $\varepsilon$, where $\delta$ is the angle between the internal rotor axis and the $a$-axis and $\varepsilon$ is the angle between the $b$-axis and the projection of the internal rotor axis onto the $b c$-plane, which is fixed to 0 in this case due to the almost $\mathrm{C}_{\mathrm{s}}$ symmetry of vinyl acetate. The fitted parameters are given as Fit I in Table 1. A list of all transition frequencies is available in the Supporting Information (Table 1S). In a second fit (Fit II in Table 1), the internal rotation parameters were fixed to the values obtained from Fit I and only the A species lines were fitted. Table 1S also contains the residuals of all 90 transitions in Fit II.

The program XIAM uses the Combined Axis Method (CAM) where the internal rotation problem is set up in the principal axis system. The Hamiltonian matrix is subsequently transformed into individual rho axis systems for each internal rotor, and Coriolis coupling terms can be eliminated. In the rho axis system, the eigenvalues are calculated in the product basis of 
symmetric top functions for the overall rotation and linear combinations of free rotor functions for the torsion. Finally, the eigenvalue matrix is transformed back to the principal axis system.

As an alternative, a fit of the same 191 transitions was performed using the program ERHAM. ${ }^{12}$ This program is often used to fit rotational spectra of molecules with one or two internal rotors. ERHAM sets up and solves an Effective Rotational HAMiltonian. The frame symmetry can be $\mathrm{C}_{s}$ or $\mathrm{C}_{1}$ for single or non-equivalent rotors and $\mathrm{C}_{2}, \mathrm{C}_{2 \mathrm{v}}$, or $\mathrm{C}_{\mathrm{s}}$ for equivalent rotors. Parameters which are comparable to those fitted by the program XIAM are presented as Fit III (Table 1), additional parameters in Table 2. The residuals of all transitions are also available in Table 1S in the Supporting Information.

Furthermore, the program BELGI-Cs was used to include the microwave data measured in Aachen and the millimeterwave data published in Ref. 10 in a global fit. BELGI-Cs uses the Rho Axis Method (RAM), and all parameters obtained in the fit are referred to the rho axis system. Many higher order terms, not only in the total angular momentum $\mathbf{P}$ but also in the angular momentum of the internal rotor $\mathbf{P}_{\alpha}$, and in cross-terms between them, can be fitted. BELGI-Cs uses a two-step diagonalization procedure, which was described in details in Ref. 3 and 13 and will not be repeated here. Some parameters are transformed in the principal axis system by a rotation about the $c$-axis and indicated as Fit V in Table 1. The BELGI-Cs parameters in the rho axis system are summarized in Table 3 . All fitted transitions along with their residuals are listed in Table 2S.

\section{QUANTUM CHEMICAL CALCULATIONS}

Potential energy surfaces - conformational analysis. One of the first quantum chemical results for vinyl acetate were obtained in 1976 by Aroney et al. using the program GAUSSIAN 70 and standard LCAO self-consistent-field molecular orbital theory. ${ }^{19}$ Calculations at the MP2/6- 
$311++\mathrm{G}(\mathrm{d}, \mathrm{p})$ level of theory in Ref. 10 exhibited three stable conformers. This method-basis set combination is widely used in the spectroscopic community ${ }^{20-22}$ and has become one of the most often used levels, which was applied for all molecules studied in Aachen in the last few years. Unlike the case of allyl acetate, where the vinyl group is tilted out of the $\mathrm{CH}_{3}(\mathrm{C}=\mathrm{O}) \mathrm{O}$ plane by an angle of approximately $120^{\circ},{ }^{1}$ in the most stable conformer of vinyl acetate, all heavy atoms are almost located in a mirror plane (see Figure 3). The vinyl group is tilted by a small angle of $7^{\circ}$ out of the symmetry plane of the ester group. This is interesting, since the same effect occurs in many molecules investigated in Aachen like ethyl methyl ketone, ${ }^{23}$ diethyl ketone, ${ }^{24}$ ethyl valerate, ${ }^{25}$ and methyl isobutyl ketone. ${ }^{26}$ We thus decided to study the conformational landscape of vinyl acetate in more detail by calculating a potential energy surface (PES) at the MP2/6-311++G(d,p) level of theory using the GAUSSIAN 09 program package. ${ }^{27}$ Two dihedral angles $\varphi_{1}=\angle\left(\mathrm{O}_{6}, \mathrm{C}_{5}, \mathrm{O}_{7}, \mathrm{C}_{8}\right)$ and $\varphi_{2}=\angle\left(\mathrm{C}_{5}, \mathrm{O}_{7}, \mathrm{C}_{8}, \mathrm{C}_{9}\right)$ were varied in a grid of $10^{\circ}$ (for atom number see Figure 3), while all other geometry parameters were allowed to relax. The corresponding energies were parameterized by a two-dimensional Fourier expansion based on terms representing the totally symmetric functions of $\varphi_{1}$ and $\varphi_{2}$; the Fourier coefficients are given in Table 3S in the Supporting Information. Using these coefficients, the PES could be drawn as a contour plot visualized in Figure 4. In agreement with the results of Velino et al., ${ }^{10}$ the PES shows two possible trans conformers at $\left(\varphi_{1}, \varphi_{2}\right)=\left(0^{\circ}, 180^{\circ}\right)$ and $\left(0^{\circ}, 0^{\circ}\right)$ and an enantiomeric pair of a cis conformer at $\left(180^{\circ}, 180^{\circ} \pm 50^{\circ}\right)$. An extremely broad minimum exists in the region centered at $\varphi_{1}=0^{\circ}$ and $\varphi_{2}=180^{\circ}$, which corresponds to the most stable conformer (conformer I) with a $C_{s}$ symmetry. Another minimum is located at $\varphi_{1}=\varphi_{2}=0^{\circ}$ which presents the other trans conformer (conformer II). This minimum is not well pronounced and looks like a maximum in Figure 4. However, in higher resolution, as shown in Figure 1S in the Supporting Information, a 
minimum can be clearly recognized. The stabilization energy is approximately $12.6 \mathrm{~kJ} \cdot \mathrm{mol}^{-1}$ higher than that of conformer I. From our experience, it is unlikely to observe conformer II under molecular beam conditions. Two minima with an energy of about $28 \mathrm{~kJ} \cdot \mathrm{mol}^{-1}$ are located at $\varphi_{1}=$ $180^{\circ}$ and $\varphi 2=180^{\circ} \pm 50^{\circ}$ which represent an enantiomeric pair of the cis conformer (conformer III/III*). In agreement with our investigations on many esters like ethyl acetate, ${ }^{3}$ ethyl pivalate ${ }^{28}$ as well as the theoretical studies of Oki et al. ${ }^{29}$ and Aroney et al. ${ }^{19}$, cis esters are much higher in energy than trans esters. Therefore, we focused only on conformer I of vinyl acetate in the present study. It should be noted that we define the trans conformation as indicated in Figure 3 and Ref. 29, which is different from the definition in Refs. 10 and 19. The coordinates of the most stable conformer I are given in Table 4S in the Supporting Information.

Calculations at the B3LYP/6-311++G(d,p) level of theory show a more distinctive minimum for conformer II. The enantiomeric pair of conformer III/III* collapses into a single broad minimum. No significant changes of the absolute minimum (conformer I) can be recognized. The corresponding PES is illustrated in Figure 5, the Fourier coefficients are also listed in Table $3 S$.

A potential curve obtained by rotating the vinyl group around the $\mathrm{O}_{7}-\mathrm{C}_{8}$ bond shown in Figure 6 almost corresponds to a cut of the PES through $\varphi_{1}=0^{\circ}$. There, the dihedral angle $\varphi_{2}$ was varied in a grid of $10^{\circ}$; all other parameters were optimized (in the PES, $\varphi_{1}$ was also fixed). Due to the $\mathrm{C}_{\text {s }}$ symmetry of the $\mathrm{CH}_{3}(\mathrm{C}=\mathrm{O}) \mathrm{O}$ frame, it was sufficient to vary $\varphi_{2}$ from $0^{\circ}$ to $180^{\circ}$. Calculations at the MP2/cc-pVTZ level were additionally performed. The Fourier coefficients are summarized in Table 5S. A closer look at the minimum region calculated in $1^{\circ}$ step width at the MP2/6-311++G(d,p) level shows clearly a double minimum for conformer I with two minima at 
$\varphi_{2}=180^{\circ} \pm 7^{\circ}$, whereas calculations at the B3LYP/6-311++G(d,p) level indicate a single minimum at $\varphi_{2}=180^{\circ}$.

Internal rotation. The barrier to internal rotation of the acetyl methyl group in vinyl acetate was calculated at different levels of theory by varying the dihedral angle $\varphi_{3}=\angle\left(\mathrm{O}_{6}, \mathrm{C}_{5}, \mathrm{C}_{1}, \mathrm{H}_{4}\right)$ in a grid of $10^{\circ}$. Only a rotation of $120^{\circ}$ was needed due to the $\mathrm{C}_{3 \mathrm{v}}$ symmetry of the methyl group. The potential curves were parametrized by Fourier expansions. The barrier heights, some sets of Fourier coefficients, and three potential curves calculated at the B3LYP/cc-pVQZ, MP2/cc-pVTZ, and CCSD/cc-pVDZ levels of theory are available in Table 6S, Table 7S, and Figure 2S, respectively, in the Supporting Information. We also calculated two PES at the MP2/6-311++G(d,p) and B3LYP/6-311++G(d,p) levels (given in Figure 3S and 4S) where two dihedral angles $\varphi_{1}$ and $\varphi_{3}$ as well as $\varphi_{2}$ and $\varphi_{3}$ were varied in a grid of $10^{\circ}$. From these PES, no significant couplings between the motions could be observed.

Basis set variation. For the most stable conformer I, optimizations at different levels of theory with the HF, B3LYP, MP2, and CCSD methods were carried out in order to explore the variation of molecular parameters with the method applied. The rotational constants $A, B, C$, the acetyl methyl barrier to internal rotation, the angles of the internal rotor in the principal axes of inertia, and the dihedral angles $\varphi_{1}$ and $\varphi_{2}$ are indicated in Table $6 \mathrm{~S}$ in the Supporting Information. Additionally, harmonic frequency calculations were carried out for the HF, B3LYP, and MP2 methods to verify whether the geometries were transition states or stable conformers.

\section{RESULTS AND DISCUSSION}

The program XIAM achieves a standard deviation of $92.3 \mathrm{kHz}$ for 191 microwave transitions (Fit I in Table 1), which is abnormally 46 times larger than our estimated experimental accuracy 
of $2 \mathrm{kHz}$. The fit can be improved by fixing the internal rotational parameters to the values obtained from the global fit and fitting only A species transitions. The standard deviation is then significantly reduced to $1.2 \mathrm{kHz}$ (Fit II in Table 1), which shows that the program XIAM can fit A species transitions of vinyl acetate perfectly but not the E species. This abnormally large standard deviation is often observed with the XIAM code when the internal rotor axis is almost in the middle of the $a$ - and $b$-axis ( $\left.\angle(\mathrm{i}, a) \approx \angle(\mathrm{i}, b) \approx 45^{\circ}\right)$, and the barrier is rather low.

The global fit with the program ERHAM yields a very good standard deviation of $4.9 \mathrm{kHz}$. The rotational constants, centrifugal distortion constants, and the angles between the internal rotor axis and the principal axes are in reasonable agreement with the values obtained by XIAM. Using the ERHAM code, some effective parameters are fitted, but unfortunately, the $V_{3}$ potential cannot be deduced easily.

The program BELGI-Cs can fit 96 millimeterwave and 191 microwave transitions globally using 18 parameters to standard deviations of $67.8 \mathrm{kHz}$ and $2.9 \mathrm{kHz}$, respectively. The deviation found for the microwave transitions is almost the experimental resolution for isolated line (2 $\mathrm{kHz}$ ). The rotational constants $A, B, C$, centrifugal distortion constants, $V_{3}$ potential, and the $D_{\mathrm{ab}}$ parameter, which multiplies the $\mathbf{P}_{\mathrm{a}} \mathbf{P}_{b}+\mathbf{P}_{b} \mathbf{P}_{\mathrm{a}}$ operator and is due to the use of the non-principal axis system, were floated. The (reduced) rotational constant of the internal rotor $F$ was fixed to $5.56622 \mathrm{~cm}^{-1}$, the value obtained from a preliminary XIAM fit, since only transitions in the torsional ground state are available and this parameter is then strongly correlated to $V_{3}$. Finally, 6 higher-order terms between the internal rotation and the global rotation $\left(F_{\mathrm{v}}, k_{5}, c_{2}, d_{\mathrm{ab}}, D_{\mathrm{acsin} 3}\right.$, and $D_{\text {acksin3) }}$ were required to obtain a root-mean-square deviation very close to measurement accuracies. 
The BELGI fit improves the root-mean-square deviation for 96 millimeterwave transitions which are weighted $40 \mathrm{kHz}$. We note that five lines from Ref. 10 showed an observed-calculated residual four times larger than the measurement uncertainty and decided to exclude them from our fit. The $A$ rotational constant obtained from the BELGI code (after a transformation into the PAM system) differs by about $25 \mathrm{MHz}$ from the values obtained by the XIAM and ERHAM codes. This parameter is also determined with less accuracy, probably due to the strong correlations with other parameters.

The $V_{3}$ potential of the acetyl methyl group is $151.492(34) \mathrm{cm}^{-1}$ according to XIAM (Fit I), slightly different from the value in Fit IV (Ref. 10) and Fit V (BELGI-Cs). However, the reduced barrier $s=4 V_{3} / 9 F$ from the BELGI fit is very similar to that in the XIAM fit (see Table I). Comparing to the value of $98.093(12) \mathrm{cm}^{-1}$ found for allyl acetate, the barrier rises significantly. In vinyl acetate, the vinyl group is attached directly to the oxygen atom, whereas in allyl acetate, a $\mathrm{CH}_{2}$ - group is in between. In isopropenyl acetate, an internal rotation barrier of 135.3498(38) $\mathrm{cm}^{-1}$ was obtained, ${ }^{30}$ which is in between the barriers found for vinyl acetate and allyl acetate. Obviously, if the vinyl group is bound directly to the ester group, $\pi$-electron conjugation, extending from the vinyl double bond to the ester group, seems possible and could increase the barrier. In allyl acetate, the vinyl group cannot conjugate with the carbonyl group and the barrier remains near $100 \mathrm{~cm}^{-1}$. The electronic and structural effects on internal rotation barrier by an interaction of the methyl group with the $\pi$ system via hyperconjugation has been discussed by Spangler, ${ }^{31}$ however, mainly on aromatic systems. Further discussion on the torsional barrier changes in substituted toluenes due to $\pi$ molecular orbital orientation effect, $\pi^{*} \leftarrow \pi$ excitation, and $\pi$ ionization was also given in the overview written by Weisshaar. ${ }^{32}$ We will continue the work on unsaturated acetates to study this feature in detail. 
The $B$ and $C$ rotational constants match the values calculated at the MP2/6-311++G(d,p) level of theory almost exactly; the $A$ rotational constant differs by $105 \mathrm{MHz}$. Calculations at the B3LYP/cc-pVTZ level of theory yielded the best agreement with the experimental values for all rotational constants (see Table $6 \mathrm{~S}$ ). The barrier height varies in a wide range from $93 \mathrm{~cm}^{-1}$ to 225 $\mathrm{cm}^{-1}$ and depends strongly on the chosen method-basis set combination.

Finally, quantum chemical calculations carried out at our most often used level of theory, $\mathrm{MP} 2 / 6-311++\mathrm{G}(\mathrm{d}, \mathrm{p})$, show that the most stable conformer is located at $\left(\varphi_{1}, \varphi_{2}\right)=\left(0^{\circ}, 180^{\circ} \pm 7^{\circ}\right)$ and the $C_{s}$ conformation at $\left(\varphi_{1}, \varphi_{2}\right)=\left(0^{\circ}, 180^{\circ}\right)$ is a transition state. We tried to measure $c$-type transitions using polarizing pulses with a power of $2 \mathrm{~W}$, whereas $b$-type transitions are already over-polarized with a few $\mathrm{mW}$. The absence of $c$-type transitions suggests that the effective structure of vinyl acetate has a $\mathrm{C}_{\text {s }}$ symmetry. However, due to the low $c$-component of the dipole moment ( 0.11 Debye) and a possible tunneling process between two enantiomers at $\varphi=+7^{\circ}$ and $-7^{\circ}$, it is difficult to decide by the absence of $c$-type transitions, whether the output power is not sufficient, a tunneling exists, or the real molecular structure indeed has a symmetry plane.

\section{CONCLUSION}

The microwave spectrum of vinyl acetate was measured using two MB-FTMW spectrometers and reproduced by three program codes XIAM, ERHAM, and BELGI-Cs. The program XIAM can fit the A species to a standard deviation of only $1.2 \mathrm{kHz}$. For the E species, the predictive power of XIAM is not satisfactory. The program ERHAM enables a fit of the microwave data set with the standard deviation close to experimental resolution. However, some effective tunneling parameters had to be added while the barrier to internal rotation cannot be obtained directly. Using the program BELGI-Cs, a global fit including both, the microwave and the millimeter wave transitions, was carried out and the whole data set with 287 torsional transitions was fitted 
using 18 parameters. The barrier height is determined with high accuracy to be $151.492(34) \mathrm{cm}^{-1}$ and $158.5787(52) \mathrm{cm}^{-1}$ using the program XIAM and BELGI, respectively. For a conformational analysis, potential energy surfaces were calculated, whereby three stable conformers were observed. The potential curve obtained by rotating the vinyl group was carried out at different levels of theory. Calculations at the MP2/6-311++G(d,p) level yielded a double minimum potential where the vinyl group is tilted against the ester frame by an angle of approximately $7^{\circ}$.

\section{ACKNOWLEDGMENT}

We thank P. Groner for making his ERHAM code and I. Kleiner for making her BELGI-Cs code available to the spectroscopic community. The Land Nordrhein-Westfalen and Université de Paris-Est Créteil are greatly acknowledged for funds. We also thank the IT Center of the RWTH Aachen University for free computer time. V. V. thanks the Fond der Chemischen Industrie (VCI) for a fellowship. A. J. thanks the Groupe de Recherche International GdRI HiResMIR for financial support to travel to RWTH Aachen University.

\section{AUTHOR INFORMATION}

\section{Corresponding Author}

* Tel: +33 1451765 53. E-mail: lam.nguyen@lisa.u-pec.fr

ASSOCIATED CONTENT

Supporting Information. Frequency lists, Fourier coefficients of the PES and potential curves, coordinates of conformer I, calculated molecular parameters of conformer I at different levels of 
theory, supplementary figures. This material is available free of charge via the Internet at http://pubs.acs.org.

\section{REFERENCES}

(1) Nguyen, H. V. L.; Mouhib, H.; Stahl W.; Kleiner I. The Microwave Spectrum of Allyl Acetate. Mol. Phys. 2010, 108, 763-770.

(2) Nguyen, H. V. L.; Kleiner I.; Shipman, S. T.; Mae, Y.; Hirose, K.; Hatanaka, S.; Kobayashi, K. Extension of the Measurement, Assignment, and Fit of the Rotational Spectrum of the Two-Top Molecule Methyl Acetate. J. Mol. Spectrosc. 2014, 299, 17-21.

(3) Jelisavac, D.; Cortés-Gómez, D. C., Nguyen, H. V. L.; Sutikdja, L. W.; Stahl, W.; Kleiner, I. The Microwave Spectrum of the trans Conformer of Ethyl Acetate. J. Mol. Spectrosc. 2009, $257,111-115$.

(4) Sutikdja, L. W.; Stahl, W.; Sironneau, V.; Kleiner, I. Structural Studies of n-Propyl Acetate by Means of Microwave Spectroscopy and Quantum Chemistry Calculations. To be published.

(5) Attig, T.; Sutikdja, L. W.; Kannengießer, R.; Kleiner, I.; Stahl, W. The Microwave Spectrum of n-Butyl Acetate. J. Mol. Spectrosc. 2013, 284-285, 8-15.

(6) Attig, T.; Kannengießer, R.; Kleiner, I.; Stahl, W. Conformational Analysis of n-Pentyl Acetate Using Microwave Spectroscopy. J. Mol. Spectrosc. 2013, 290, 24-30. 
(7) Attig, T.; Kannengießer, R.; Kleiner, I.; Stahl, W. The Microwave Spectrum of n-Hexyl Acetate and Structural Aspects of n-Alkyl Acetates. J. Mol. Spectrosc. 2014, 298, 47-53.

(8) Mouhib, H.; Jelisavac, D.; Stahl, W.; Wang, R.; Kalf, I.; Englert, U. The Conformation of Odorants in Different States of Aggregation: A Joint Venture in Microwave Spectroscopy and XRay Diffraction. Chem. Phys. Chem. 2011, 12, 761-764.

(9) Sutikdja, L. W.; Jelisavac, D.; Stahl, W.; Kleiner, I. Structural Studies on Banana Oil, Isoamyl Acetate, by Means of Microwave Spectroscopy and Quantum Chemical Calculations. Mol. Phys. 2012, 110, 2883-2893.

(10) Velino, B.; Maris, A.; Melandri, S.; Caminati, W. Millimeter Wave Free-Jet Spectrum of Vinyl Acetate. J. Mol. Spectrosc. 2009, 256, 228-231.

(11) Hartwig, H.; Dreizler, H. The Microwave Spectrum of trans-2,3-Dimethyloxirane in Torsional Excited States. Z. Naturforsch. 1996, 51a, 923-932.

(12) Groner, P. Effective Rotational Hamiltonian for Molecules with Two Periodic LargeAmplitude Motions. J. Chem. Phys. 1997, 107, 4483-4498.

(13) Hougen, J. T.; Kleiner, I.; Godefroid, M. Selection Rules and Intensity Calculations for a Cs Asymmetric Top Molecule Containing a Methyl Group Internal Rotor. J. Mol. Spectrosc. 1994, 163, 559-586.

(14) Kisiel, Z. http://www.ifpan.edu.pl/ kisiel/prospe.htm.

(15) Andresen, U.; Dreizler, H.; Grabow, J.-U.; Stahl, W. An Automatic Molecular Beam Microwave Fourier Transform Spectrometer. Rev. Sci. Instrum. 1990, 61, 3694-3699. 
(16) Grabow, J.-U.; Stahl, W.; Dreizler, H. A Multioctave Coaxially Oriented Beam Resonator Arrangement Fourier-Transform Microwave (COBRA-FTMW) Spectrometer. Rev. Sci. Instrum. 1996, 67, 4072-4084.

(17) Merke, I.; Stahl, W.; Dreizler, H. A Molecular Beam Fourier Transform Microwave Spectrometer in the Range 26.5 to $40 \mathrm{GHz}$. Tests of Performance and Analysis of the D- and ${ }^{14} \mathrm{~N}-$ Hyperfine Structure of Methylcyanide-d1. Z. Naturforsch. 1994, 49a, 490-496.

(18) Grabow, J.-U.; Stahl, W. A Pulsed Molecular Beam Microwave Fourier Transform Spectrometer with Parallel Molecular Beam and Resonator Axes. Z. Naturforsch. 1990, 45a, $1043-1044$.

(19) Aroney, M. J.; Bruce, E. A. W.; John, I. G.; Radom, L.; Ritchie, G. L. D. Conformations of Vinyl Formate and Vinyl Acetate. Aust. J. Chem. 1976, 29, 581-587.

(20) Aviles-Moreno, J. R.; Demaison, J.; Huet, T. R. Conformational Flexibility in Hydrated Sugars: the Glycolaldehyde-Water Complex. J. Am. Chem. Soc. 2006, 128, 10467-10473.

(21) Grabow, J.-U.; Mata, S.; Alonso, J. L.; Peña, I.; Blanco, S.; López, J. C.; Cabezas C. Rapid Probe of the Nicotine Spectra by High-Resolution Rotational Spectroscopy. Phys. Chem. Chem. Phys. 2011, 13, 21063-21069

(22) Pérez, C.; Muckle, M. T.; Zaleski, D. P.; Seifert, N. A.; Temelso, B.; Shields, G. C.; Kisiel, Z.; Pate, B. H. Structures of Cage, Prism, and Book Isomers of Water Hexamer from Broadband Rotational Spectroscopy. Science 2012, 336, 897-901.

(23) Nguyen, H. V. L.; Van, V.; Stahl, W.; Kleiner, I. The Effects of Two Internal Rotations in the Microwave Spectrum of Ethyl Methyl Ketone. J. Chem. Phys. 2014, 140, 214303. 
(24) Nguyen, H. V. L.; Stahl, W. The Rotational Spectrum of Diethyl Ketone. Chem. Phys. Chem. 2011, 12, 1900-1905.

(25) Mouhib, H.; Stahl, W. Conformational Analysis of Green Apple Flavour: The Gas-Phase Structure of Ethyl Valerate Validated by Microwave Spectroscopy. Chem. Phys. Chem. 2012, 13, $1297-1301$.

(26) Zhao, Y.; Stahl, W.; Nguyen, H. V. L. Ketone Physics - Structure, Conformations, and Dynamics of Methyl Isobutyl Ketone Explored by Microwave Spectroscopy and Quantum Chemical Calculations. Chem. Phys. Lett. 2012, 545, 9-13.

(27) Frisch, M. J.; Trucks, G. W.; Schlegel, H. B.; Scuseria, G. E.; Robb, M. A.; Cheeseman, J. R.; Scalmani, G.; Barone, V.; Mennucci, B.; Petersson, G. A et al. Gaussian 09, Revision A.02, Gaussian, Inc.; Wallingford CT, 2009.

(28) Mouhib, H.; Zhao, Y.; Stahl, W. Two Conformers of Ethyl Pivalate Studied by Microwave Spectroscopy. J. Mol. Spectrosc. 2010, 261, 59-62.

(29) Oki, M.; Nakanishi, H. Conformations of the Ester Group. Bul. Chem. Soc. Japan 1970, $43,2558-2566$.

(30) Nguyen, H.V.L.; Stahl, W. The Microwave Spectrum of Isopropenyl Acetate. J. Mol. Spectrosc. 2010, 264, 120-124.

(31) Spangler, L. H. Structural Information from Methyl Internal Rotation Spectroscopy. Annu. Rev. Phys. Chem. 1997, 48, 481-510.

(32) Jennings K. R. Fundamentals and Applications of Gas Phase Ion Chemistry, Kluwer Academic Publischers 1999, Vol. 521, 307-334. 


\section{TABLES}

Table 1. Molecular parameters of vinyl acetate obtained by the programs XIAM, ERHAM, and BELGI-Cs.

\begin{tabular}{|c|c|c|c|c|c|c|}
\hline Parameter $^{\mathrm{a}}$ & Unit & $\begin{array}{l}\text { Fit I } \\
\text { XIAM }\end{array}$ & $\begin{array}{l}\text { Fit II } \\
\text { XIAM }\end{array}$ & $\begin{array}{l}\text { Fit III } \\
\text { ERHAM }\end{array}$ & $\begin{array}{l}\text { Fit IV } \\
\text { Ref. } 10\end{array}$ & $\begin{array}{l}\text { Fit V } \\
\text { BELGI-Cs }\end{array}$ \\
\hline $\bar{A}$ & $\mathrm{GHz}$ & $9.400225(19)$ & $9.40023177(11)$ & $9.40126497(75)$ & $9.40186(4)$ & $9.375162(96)$ \\
\hline$B$ & $\mathrm{GHz}$ & $2.240145(24)$ & $2.240142373(34)$ & $2.24171253(21)$ & $2.241742(6)$ & $2.243104(21)$ \\
\hline$C$ & $\mathrm{GHz}$ & $1.831944(17)$ & $1.831941565(34)$ & $1.83242483(19)$ & $1.832332(7)$ & $1.8329208(21)$ \\
\hline$\Delta_{J}$ & $\mathrm{kHz}$ & $0.1725(82)$ & $0.18107(17)$ & $0.17756(93)$ & $0.15(1)$ & $0.1643(11)$ \\
\hline$\Delta_{J K}$ & $\mathrm{kHz}$ & $1.740(54)$ & $1.7955(12)$ & $1.8251(63)$ & $1.84(1)$ & \\
\hline$\Delta_{K}$ & $\mathrm{kHz}$ & $8.51(38)$ & $9.3848(57)$ & $7.637(72)$ & $10.7(6)$ & \\
\hline$\delta_{J}$ & $\mathrm{kHz}$ & $0.0416(27)$ & $0.036955(54)$ & $0.03594(31)$ & $-0.0347(7)$ & \\
\hline$\delta_{K}$ & $\mathrm{kHz}$ & $0.52(13)$ & $0.9284(23)$ & $0.647(18)$ & $-0.0071(4)$ & \\
\hline \multirow[t]{2}{*}{$V_{3}$} & $\mathrm{~cm}^{-1}$ & $151.492(34)$ & $151.492^{\mathrm{b}}$ & & $155.07(9)$ & $158.5787(52)$ \\
\hline & $\mathrm{kJ} \cdot \mathrm{mol}^{-1}$ & $1.81224(40)$ & $1.81224^{\mathrm{b}}$ & & $1.855(1)$ & \\
\hline$s^{\mathrm{c}}$ & & 12.5981 & & & & 12.66192 \\
\hline$I_{\alpha}$ & $\mathrm{u} \AA^{2}$ & $3.28858(59)$ & $3.28858^{\mathrm{b}}$ & $3.3258(51)$ & $3.215(2)$ & $3.21012(84)$ \\
\hline$\angle(\mathrm{i}, a)$ & $\circ$ & $41.3205(89)^{\mathrm{d}}$ & $41.3205^{\mathrm{b}}$ & $37.53(11)$ & $41.05(1)$ & $41.30950(86)$ \\
\hline$\angle(\mathrm{i}, b)$ & $\circ$ & $48.6795(89)^{\mathrm{d}}$ & $48.6795^{\mathrm{b}}$ & $52.47(11)$ & $48.95(1)$ & $48.69050(86)$ \\
\hline $\mathrm{D}_{\mathrm{pi} 2 J}$ & $\mathrm{MHz}$ & $0.1531(28)$ & $0.1531^{\mathrm{b}}$ & & $11(1)$ & \\
\hline $\mathrm{D}_{\mathrm{pi} 2-}$ & $\mathrm{MHz}$ & $0.0916(15)$ & $0.0916^{\mathrm{b}}$ & & & \\
\hline$\sigma^{\mathrm{e}}$ & $\mathrm{MHz}$ & 0.0923 & 0.0012 & 0.0049 & 0.08 & $0.0678^{\mathrm{f}} / 0.0029^{\mathrm{g}}$ \\
\hline $\mathrm{N}_{\mathrm{A}} / \mathrm{N}_{\mathrm{E}}{ }^{\mathrm{h}}$ & & $90 / 101$ & $90 / 0$ & $90 / 101$ & 101 & $147 / 140$ \\
\hline
\end{tabular}

a All parameters refer to the principal axis system. Watson's A reduction in $\mathrm{I}^{\mathrm{r}}$ representation was used. ${ }^{\mathrm{b}}$ Fixed to the values in Fit I (see text). ${ }^{\mathrm{c}}$ Reduced barrier $s=4 V_{3} / 9 F$. ${ }^{\mathrm{d}}$ Derived from $\delta, \angle(\mathrm{i}, c)$ is fixed to $90.0^{\circ}$ in all fits due to $\mathrm{C}_{\mathrm{s}}$ symmetry. ${ }^{\mathrm{e}}$ Standard deviation of the fit. ${ }^{\mathrm{f}}$ Millimeterwave data. ${ }^{\mathrm{g}}$ Microwave data. ${ }^{\mathrm{h}}$ Number of the $\mathrm{A}\left(\mathrm{N}_{\mathrm{A}}\right)$ and $\mathrm{E}$ species lines $\left(\mathrm{N}_{\mathrm{E}}\right)$. 
Table 2: Additional molecular parameters of vinyl acetate fitted by the program ERHAM. For the nomenclature, see Ref. (12).

\begin{tabular}{lll}
\hline \hline Parameter & Unit & Value \\
\hline$\rho$ & & $0.049879(20)$ \\
$\beta$ & $\circ$ & $10.380(38)$ \\
$\epsilon 10$ & $\mathrm{GHz}$ & $-4.43447(84)$ \\
{$\left[\mathrm{G}_{\mathrm{a}}\right]_{10}$} & $\mathrm{MHz}$ & $77.71(11)$ \\
{$\left[\mathrm{G}_{\mathrm{b}}\right]_{10}$} & $\mathrm{MHz}$ & $2.15(15)$ \\
{$[\mathrm{A}-(\mathrm{B}+\mathrm{C}) / 2]_{10}$} & $\mathrm{MHz}$ & $2.2384(44)$ \\
{$[(\mathrm{B}+\mathrm{C}) / 2]_{10}$} & $\mathrm{kHz}$ & $-36.2(30)$ \\
{$[(\mathrm{B}-\mathrm{C}) / 4]_{10}$} & $\mathrm{kHz}$ & $-9.2(14)$ \\
{$\left[\Delta_{J K}\right]_{10}$} & $\mathrm{kHz}$ & $0.3403(40)$ \\
{$\left[\Delta_{K}\right]_{10}$} & $\mathrm{kHz}$ & $4.715(41)$ \\
{$\left[\delta_{J}\right]_{10}$} & $\mathrm{kHz}$ & $0.00132(21)$ \\
{$\left[\delta_{K}\right]_{10}$} & $\mathrm{kHz}$ & $0.0707(84)$ \\
\hline \hline
\end{tabular}


Table 3: Spectroscopic constants of vinyl acetate in the RAM system obtained with the program BELGI-Cs.

\begin{tabular}{|c|c|c|c|c|}
\hline Operator $^{\mathrm{a}}$ & Parameter $^{\mathrm{b}}$ & $\begin{array}{l}\text { BELGI-Cs } \\
\text { notation }\end{array}$ & Unit & Value $^{\mathrm{c}}$ \\
\hline $\mathbf{P}_{\mathrm{a}}^{2}$ & $A$ & $\mathrm{OA}$ & $\mathrm{GHz}$ & $9.073193(99)$ \\
\hline $\mathbf{P}_{\mathrm{b}}^{2}$ & $B$ & $\mathrm{~B}$ & $\mathrm{GHz}$ & $2.545073(15)$ \\
\hline $\mathbf{P}_{\mathrm{c}}^{2}$ & $C$ & $\mathrm{C}$ & $\mathrm{GHz}$ & $1.8329208(20)$ \\
\hline$\left\{\mathbf{P}_{\mathrm{a}}, \mathbf{P}_{\mathrm{b}}\right\}$ & $D_{\mathrm{ab}}$ & $\mathrm{DAB}$ & $\mathrm{GHz}$ & $-1.436133(34)$ \\
\hline$\left\{\mathbf{P}_{\mathrm{a}}, \mathbf{P}_{\mathrm{b}}\right\}(1-\cos 3 \alpha)$ & $d_{a b}$ & ODAB & $\mathrm{MHz}$ & $-4.691(19)$ \\
\hline$-\mathbf{P}^{4}$ & $\Delta \mathrm{J}$ & DJ & $\mathrm{kHz}$ & $0.1643(11)$ \\
\hline$-\mathbf{P}_{\mathrm{a}}^{4}$ & $\Delta \mathrm{K}$ & DK & $\mathrm{kHz}$ & $9.789(34)$ \\
\hline $\mathbf{P}^{6}$ & $H_{J}$ & $\mathrm{HJ}$ & $\mathrm{Hz}$ & $0.0147(26)$ \\
\hline $\mathbf{P}_{\mathrm{a}}{ }^{6}$ & $H_{K}$ & $\mathrm{HK}$ & $\mathrm{Hz}$ & $14.6(15)$ \\
\hline$-2 \mathbf{P}^{2}\left(\mathbf{P}_{\mathrm{b}}^{2}-\mathbf{P}_{\mathrm{c}}^{2}\right)$ & $\delta \mathrm{J}$ & ODELN & $\mathrm{Hz}$ & $26.22(23)$ \\
\hline$-\left\{\mathbf{P}_{\mathrm{a}}^{2},\left(\mathbf{P}_{\mathrm{b}}^{2}-\mathbf{P}_{\mathrm{c}}^{2}\right)\right\}$ & $\delta \mathrm{K}$ & ODELK & $\mathrm{kHz}$ & $0.393(16)$ \\
\hline $\mathbf{P}_{\alpha}^{2}$ & $F$ & $\mathrm{~F}$ & $\mathrm{~cm}^{-1}$ & $5.56622^{\mathrm{d}}$ \\
\hline$(1 / 2)(1-\cos 3 \alpha)$ & $V_{3}$ & V3 & $\mathrm{cm}^{-1}$ & $158.5787(52)$ \\
\hline $\mathbf{P}_{\mathrm{a}} \mathbf{P}_{\alpha}$ & $\rho$ & RHORHO & unitless & $0.0457099(41)$ \\
\hline$(1-\cos 3 \alpha) \mathbf{P}^{2}$ & $F_{\mathrm{v}}$ & $\mathrm{FV}$ & $\mathrm{MHz}$ & $-4.691(19)$ \\
\hline$(1-\cos 3 \alpha) \mathbf{P}_{\mathrm{a}}^{2}$ & $k_{5}$ & AK5 & $\mathrm{MHz}$ & $99.41(33)$ \\
\hline$(1-\cos 3 \alpha)\left(\mathbf{P}_{\mathrm{b}}^{2}-\mathbf{P}_{\mathrm{c}}^{2}\right)$ & $c_{2}$ & $\mathrm{C} 2$ & $\mathrm{MHz}$ & $-2.553(16)$ \\
\hline$\left\{\mathbf{P}_{\mathrm{a}}, \mathbf{P}_{\mathrm{c}}\right\} \sin 3 \alpha$ & $D_{a c \sin 3}{ }^{\mathrm{e}}$ & DAC & $\mathrm{MHz}$ & 29.64(94) \\
\hline $\mathbf{P}_{\mathrm{a}}^{2}\left\{\mathbf{P}_{\mathrm{a}}, \mathbf{P}_{\mathrm{c}}\right\} \sin 3 \alpha$ & $D_{a c K \sin 3}{ }^{\mathrm{e}}$ & DACK & $\mathrm{MHz}$ & $0.1020(84)$ \\
\hline Weight / kHz & $\mathrm{N}_{\mathrm{A}} / \mathrm{N}_{\mathrm{E}} / \mathrm{N}^{\mathrm{f}}$ & \multicolumn{3}{|c|}{ Root mean square deviation $/ \mathrm{kHz}$} \\
\hline 5 & $90 / 101 / 191$ & \multicolumn{3}{|l|}{2.9} \\
\hline 40 & $57 / 39 / 96$ & \multicolumn{3}{|l|}{67.8} \\
\hline Not included ${ }^{g}$ & $2 / 3 / 5$ & & & \\
\hline
\end{tabular}

${ }^{a}$ All constants refer to a rho-axis system. Therefore, the inertia tensor is not diagonal and the constants cannot be directly compared to those of a principal axis system. $\mathbf{P}_{\mathrm{a}}, \mathbf{P}_{\mathrm{b}}$, and $\mathbf{P}_{\mathrm{c}}$ are the components of the overall rotational angular momentum. $\mathbf{P}_{\alpha}$ is the angular momentum of the internal rotor rotating around the internal rotor axis by an angle $\alpha .\{\mathrm{u}, \mathrm{v}\}$ is the anti-commutator uv + vu.

${ }^{\mathrm{b}}$ The product of the parameter and operator from a given row yields the term actually used in the zeroth-order torsional Hamiltonian, except for $F, \rho$, and $A$, which occur in the Hamiltonian in the form $F\left(\mathbf{P}_{\alpha-}-\rho \mathbf{P}_{\mathrm{a}}\right)^{2}+A \mathbf{P}_{\mathrm{a}}{ }^{2}$.

${ }^{\mathrm{c}}$ Statistical uncertainties are shown as one standard uncertainty in unit of the last digit.

${ }^{\mathrm{d}}$ Fixed to the value in a preliminary XIAM fit (see text).

e These two constants used to be called $D_{a c}$ and $D_{a c k}$, but we decided to rename them to emphasize the $\sin 3 \alpha$ dependence. 
${ }^{\mathrm{f}}$ Number of the A species $\left(\mathrm{N}_{\mathrm{A}}\right)$, E species lines $\left(\mathrm{N}_{\mathrm{E}}\right)$, and the total number of lines $(\mathrm{N})$ included in the fit.

${ }^{g}$ From the fit in Ref. 10, excluded since the obs.-calc. values are four times larger than the experimental resolution.

\section{FIGURES}

Figure 1. A typical spectrum of the $6_{24} \leftarrow 6_{15}$ A species transition of vinyl acetate. The experimental resolution is $2 \mathrm{kHz}$, the line width $38 \mathrm{kHz}(\mathrm{FWHH})$. The Doppler splitting is indicated by bracket. For this spectrum, 26 decays were co-added.

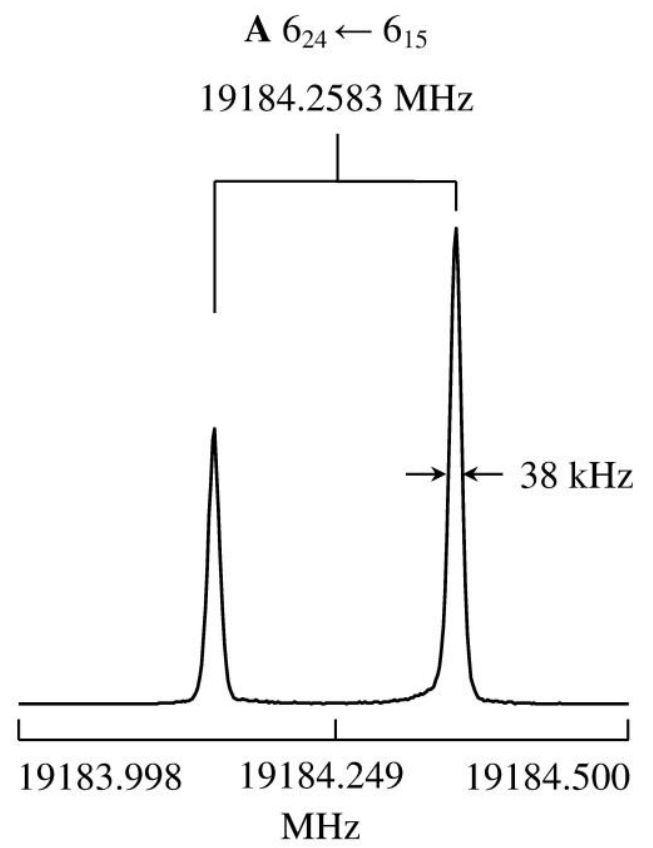


Figure 2. Two sections of a typical broadband scan of vinyl acetate covered by overlapping spectra with a step width of $0.25 \mathrm{MHz}$. For each single measurement, 50 decays were co-added. The A-E splitting of the $6_{24} \leftarrow 6_{15}$ transition is about $635 \mathrm{MHz}$. All lines are very intense $b$-type transitions. The narrow splitting on top of each line is due to over-polarization.

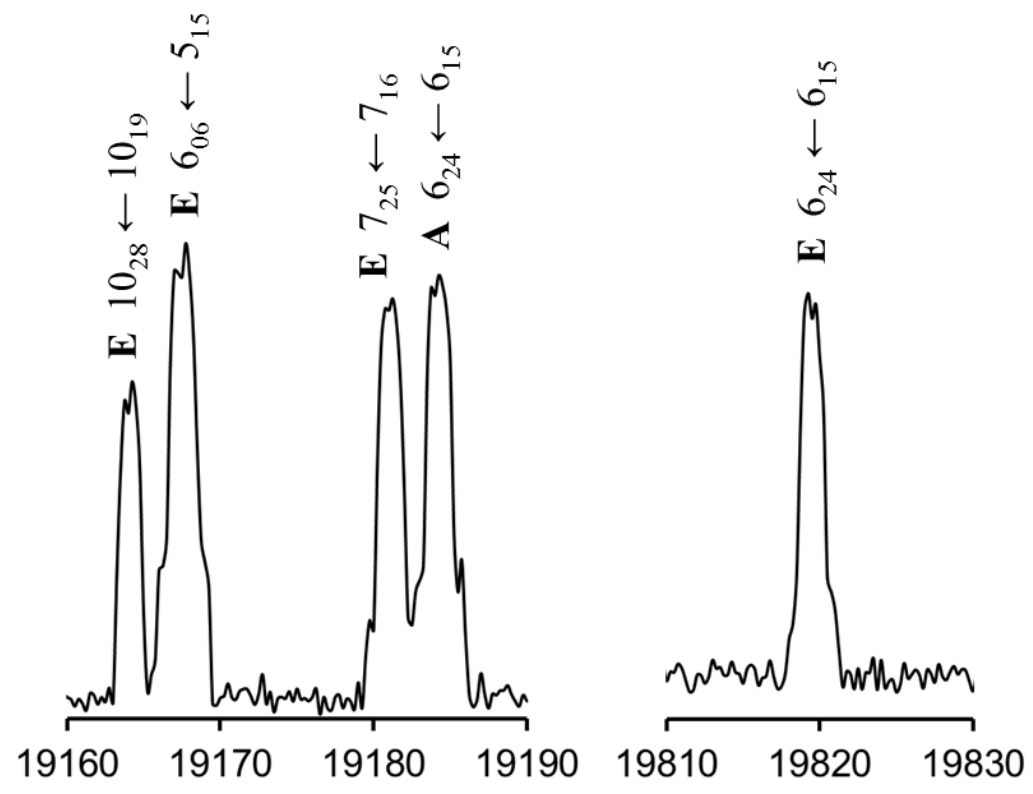

Figure 3. Geometry of the most stable trans conformer I of vinyl acetate calculated at the MP2/6-311++G(d,p) level of theory. The vinyl group is tilted by $7^{\circ}$ out of the $\mathrm{C}_{1}-\left(\mathrm{C}_{5}=\mathrm{O}_{6}\right) \mathrm{O}_{7}$ plane. The red arrow indicates the direction of the dipole vector pointing from minus to plus.

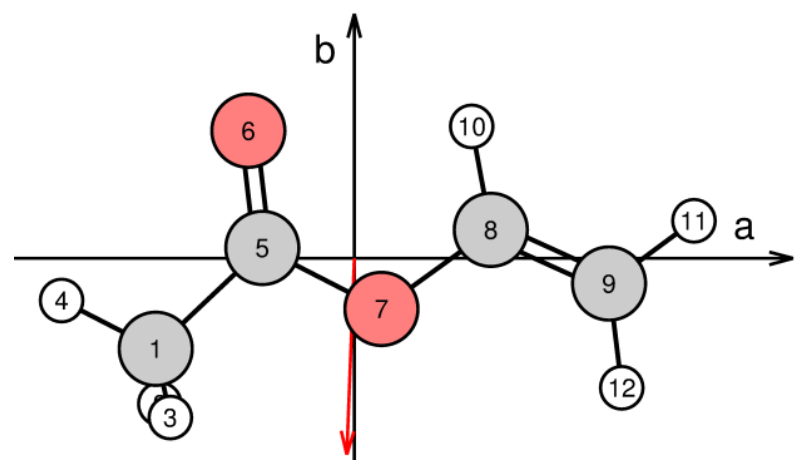


Figure 4. The potential energy surface of vinyl acetate obtained by rotating the dihedral angles $\varphi_{1}=\angle\left(\mathrm{O}_{6}, \mathrm{C}_{5}, \mathrm{O}_{7}, \mathrm{C}_{8}\right)$ (rotation around the $\mathrm{C}_{5}-\mathrm{O}_{7}$ bond) and $\varphi_{2}=\angle\left(\mathrm{C}_{5}, \mathrm{O}_{7}, \mathrm{C}_{8}, \mathrm{C}_{9}\right)$ (rotation around the $\mathrm{O}_{7}-\mathrm{C}_{8}$ bond) for a conformational analysis. Calculations were performed at the MP2/6-311++G(d,p) level of theory. The absolute energy of the lowest conformation is $\mathrm{E}=-305.7221345$ Hartree. Two stable trans conformers (I and II) as well as the enantiomeric pair of a cis conformer (III/III*) are found.

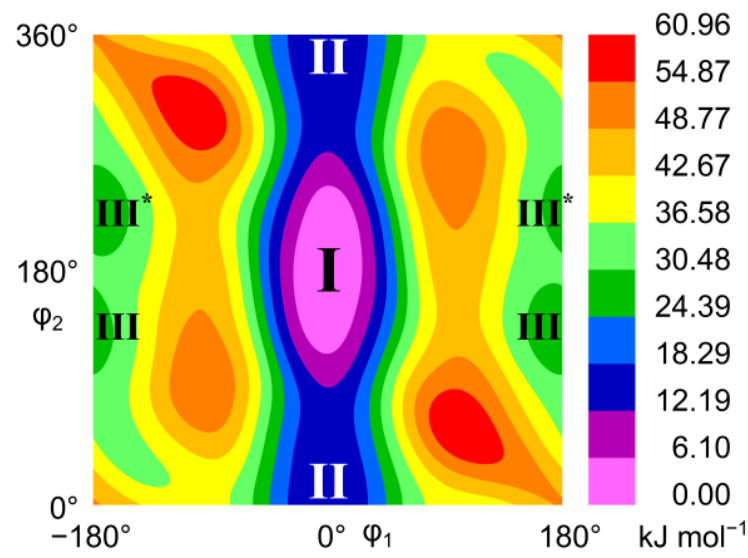

Figure 5. The potential energy surface of vinyl acetate obtained by rotating the dihedral angles $\varphi_{1}$ and $\varphi_{2}$ calculated at the B3LYP/6-311++G(d,p) level of theory. The absolute energy of the lowest conformation is $\mathrm{E}=-305.5670175$ Hartree. The enantiomeric pair III/III* in Figure 4 collapses into a single broad minimum (III).

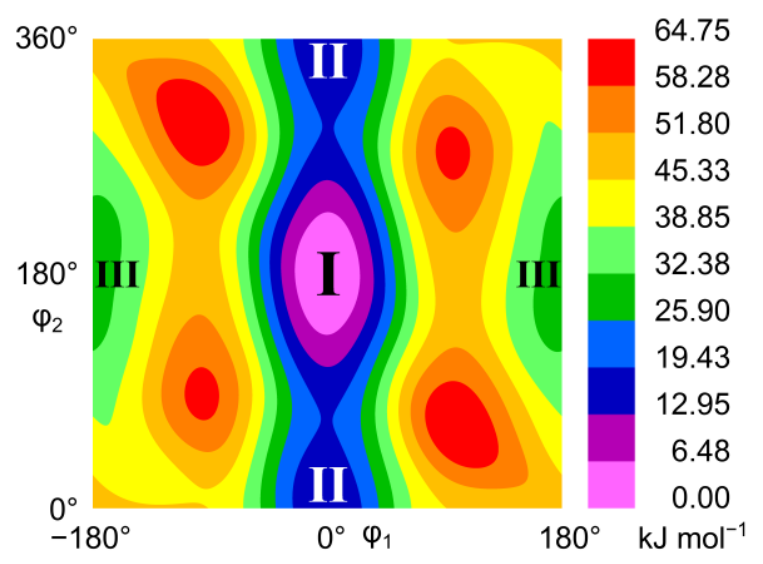


Figure 6. The potential curve of vinyl acetate obtained by rotating the vinyl group around the $\mathrm{O}_{7}-\mathrm{C}_{8}$ bond (varying the dihedral angle $\varphi_{2}=\angle\left(\mathrm{C}_{5}, \mathrm{O}_{7}, \mathrm{C}_{8}, \mathrm{C}_{9}\right)$ in a grid of $\left.10^{\circ}\right)$ calculated at the MP2/6-311++G(d,p), B3LYP/6-311++G(d,p), and MP2/cc-pVTZ levels of theory. The absolute energies of the lowest energy conformations are $E=-305.2746103$ Hartree, -306.5670175 Hartree, and -305.9079105 Hartree, respectively. A double minimum at $\varphi_{2}=180^{\circ} \pm 7^{\circ}$ can be observed by calculations at the MP2/6-311++G(d,p) level.

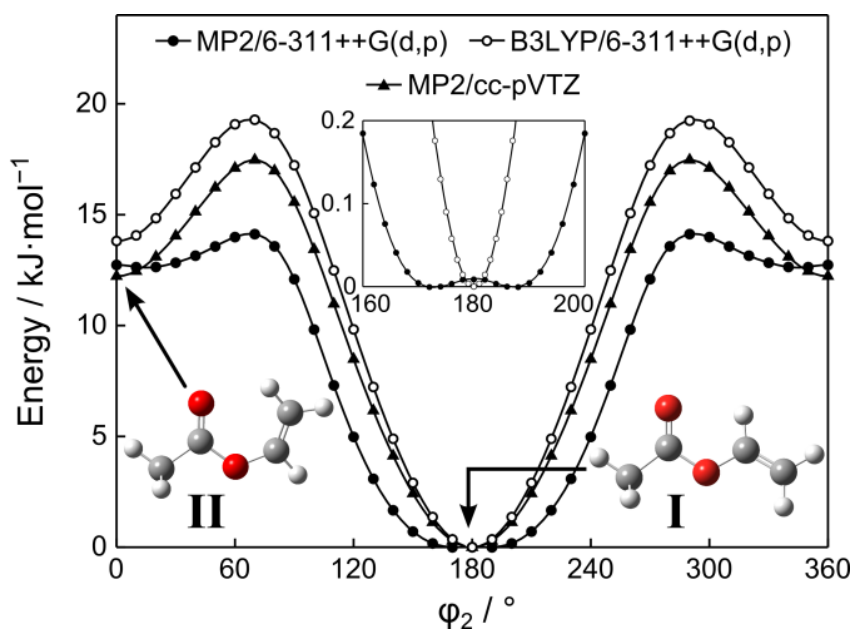


TABLE OF CONTENTS IMAGE

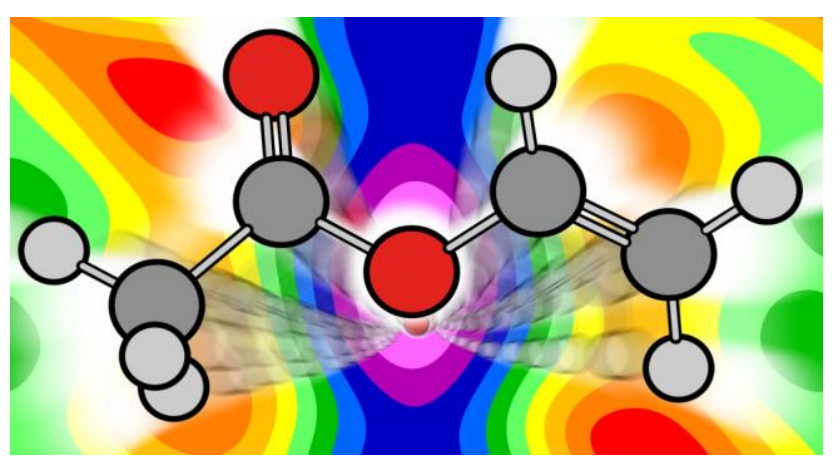

